\title{
THE ROLE OF THE SUSTAINED LOADS ON THE BEARING CAPACITY OF REINFORCED CONCRETE COLUMNS RETROFITTED BY STEEL JACKETS
}

\author{
Marco Filippo Ferrotto, Bharat Pradhan and Liborio Cavaleri \\ University of Palermo \\ Viale delle Scienze, Palermo, Italy \\ \{marcofilippo.ferrotto, bharat.pradhan, liborio.cavaleri\}@unipa.it
}

\begin{abstract}
Strengthening of reinforced concrete structures by steel jackets is a common retrofitting technique widely used in engineering practice. In most cases, reinforced concrete columns are strengthened under service loads while the columns are subjected to a certain amount of compressive stress caused by gravitational loads. In such cases, the bearing capacity for strengthened columns can be different from that obtained without existing stresses. In this paper, the effect of sustained loads in the prediction of the bearing capacity for strengthened columns is assessed by experimental, numerical, and analytical approaches. The results of the investigation revealed that the level of sustained loads at the moment of strengthening reduces the bearing capacity of columns, influencing the overall performances of retrofitted structures.
\end{abstract}

Keywords: Steel Jacketing, Confined Concrete, Sustained Loads, Preloading, Retrofitting. 


\section{INTRODUCTION}

Retrofitting of existing RC frame structures by strengthening members such as beams and columns is among the commonly adopted strategies to improve the seismic capacity of existing buildings subjected to seismic actions [1-3]. Different approaches are available nowadays and each method provides different capacity improvement depending on the mechanical behavior of the confining device [3]. For example, Fiber Reinforced Polymers (FRP) sheets provide to the columns passive confining mechanism [4-9], and steel jackets provide semiactive or active confinement [8-15]. Other techniques can be used to increase the crosssection of the existing columns i.e. reinforced concrete jackets $[18,19]$.

Most of the available analytical and mechanical models are provided without considering the effect of existing sustained loads on the members during the strengthening, that is a common situation for reinforced concrete structures. The consequence is that, when these formulations are used for the assessment of buildings, it is not possible to consider whether the elements are already in a stressed/strained state able to change the effectiveness of the adding reinforcement $[8,17]$.

In the last years, few studies dealt with the modification of the capacity of strengthened members while loaded. In the case of FRP jacketing, the findings do not always lead to the same conclusions. Some authors state that there is no significant capacity modification [7], other authors state that there is a capacity reduction depending on the level of stress/strain acting on the columns at the moment of strengthening [20]. In the case of steel jackets, it was demonstrated that there is a reduction of the capacity depending on the level of sustained loads in the columns when the reinforcement is applied [17]. An important role belongs also to the time-dependent effects to consider the modification of the compressive strength of the concrete.

This paper focuses on the evaluation of the compressive behavior of columns strengthened by means of external steel cages considering the effect of the presence of service loads, and how this effect can change the compressive capacity with respect to the commonly known compressive behavior of confined members without preload.

A numerical model is assessed by the finite element software Abaqus CAE to realistically reproduce the physical process. Results by a recent experimental investigation are used for the calibration and the validation of the FE model, demonstrating the reliability of the proposed procedure.

\section{THEORETICAL FRAMEWORK}

Retrofitting by strengthening on existing structures is usually performed under serviceability loads (gravitational loads from beams and slabs with no live loads): the consequence is that the concrete columns are subjected to a certain stress-strain level when become strengthened. The ratio between the acting stress $\sigma(\varepsilon)$ and the compressive concrete strength $f_{c 0}$ can identify the preloading level as follows $[6,17]$ :

$$
n_{p}=\frac{P}{P_{\max }}=\frac{\sigma(\varepsilon)}{f_{c 0}} \quad \text { for } \quad 0 \leq n_{p} \leq 1
$$

After the strengthening, the column became confined only if further increasing of loads are applied, changing the behavior from plain concrete to confined concrete. This differs from the case of columns strengthened without preload and different results in terms of load-carrying capacity were found to be depending on the preloading level acting while the columns are strengthened. 
In the following sections, the physical problem is faced by means of the finite element modeling software package Simulia Abaqus CAE, reproducing the pre-loading, the confinement, and the failure compressive tests. The plasticity parameters for the concrete as well as the constitutive material modeling of steel and concrete are discussed also considering the influence of the time-dependent effects due to the concrete subjected to sustained stresses. The finite element model was calibrated on the basis of a previous experimental investigation carried out by the authors. A further validation has been made with further new experimental tests presented in the second part of the paper, demonstrating the reliability of the findings and the suitability of the realistic prediction of the process carried out by numerical approach.

It is worth stating that the authors assessed this numerical procedure in the case of FRPconfined concrete cylinders subjected to preload [6].

\section{NUMERICAL MODEL}

The finite element software ABAQUS CAE version 6.13 [21] was used to build a FE model of reinforced concrete columns externally confined with steel angles and plates according to the study of Ferrotto et al. [16].

The column and the steel cage were modeled with C3D8-R elements (8-node linear brick, reduced integration, hourglass control). Mesh convergence studies were carried out to observe the influence of the aspect ratio of the C3D8-R elements on the global response and to determine optimal FE mesh that provides a relatively accurate solution with low computational efforts. Elements with aspect ratio not higher than 1.5 resulted to be optimal for the numerical simulations.

Concrete prismatic specimen having dimensions of 200x200x750 $\mathrm{mm}$ and compressive strength of $25 \mathrm{MPa}$ was used. The steel cage was composed by steel angles and strips with yielding stress of $275 \mathrm{MPa}$, having dimensions of 50/50/5 (mm) and 40/4 (mm) respectively. Details of the specimen are shown in Fig. 1.

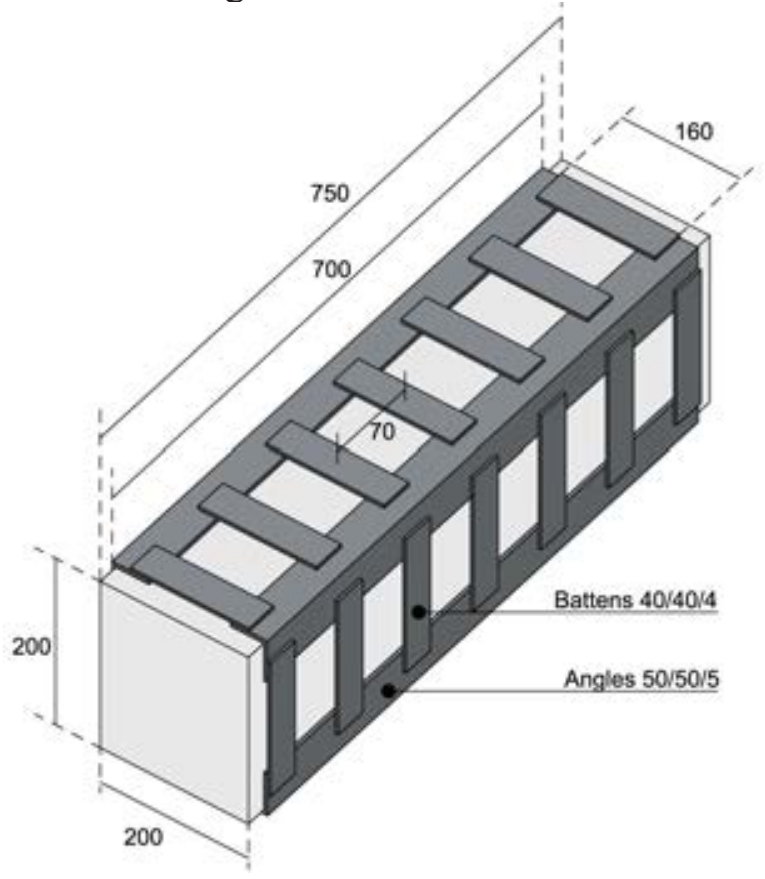

Figure 1: Geometrical configuration of the strengthened specimen. 


\subsection{Boundary conditions and interactions}

Two rigid bodies at the top and the bottom of the specimen with the translational degrees of freedom restrained for the ends except for the vertical displacement (direction of loading) were defined. "Tie-constrain" interactions were used to define the contact properties between the steel battens and the steel angles to simulate the welding of the steel so that there was no relative motion between them. The same interactions were defined also between the concrete column and the steel angles. The latter assumption allows to define a perfect contact between steel angles and concrete (avoiding potential convergence problems due to other types of contact modeling) provided that an adequate material constitutive law is defined for the steel angles.

\subsection{Material modeling of steel}

According to Ferrotto et al. [16], during compression tests, RC Steel Jacketed columns can be loaded in two different ways, that are applying the load both to the steel angles and the concrete (angles fully-loaded) or to the concrete column only (angles indirectly-loaded). Buckling or frictional effects need to be considered in the constitutive modeling of the steel if tie-constrain interaction is used.

To take into account tangential stresses along the contact surfaces between steel angles and concrete (in the case of angles indirectly-loaded), Mohr-Coulomb criterion was adopted according to Campione et al. [15] and Ferrotto et. al. [16, 17]. If 0.5 is used as a friction coefficient $\mu$, the equivalent normal stress in the angles (fictitious yielding stress corresponding to the concrete-angles sliding) can be expressed as follows:

$$
f_{y}^{*}=\frac{2 \cdot n a \cdot l_{1} \cdot l_{0} \cdot\left(\mu \cdot f l_{\max }\right)}{n a \cdot t_{1} \cdot\left(L_{1}+t_{1}\right)}=\frac{l_{1} \cdot l_{0} \cdot f l_{\max }}{t_{1} \cdot\left(L_{1}+t_{1}\right)}
$$

in which $n_{a}$ is the number of the angles, $L_{1}$ and $l_{1}$ are the external and the internal sides of the angles in contact with the concrete column respectively, $l_{0}$ is the overall vertical length along the columns and $t_{1}$ is the thickness of the angles. For more details, please refer to the original treatment of the authors.

In the case of angles fully loaded, the model allows the evaluation of the critical stress taking into account possible buckling by the following equations:

$$
\begin{gathered}
\sigma_{c}=\frac{1}{s_{b} \cdot l_{t} \cdot t} \cdot \frac{1}{\sqrt{2 \varepsilon_{s}-\varepsilon_{s}^{2}}} \cdot\left\{2\left\lfloor\frac{l_{t}^{2} \cdot t \cdot f_{y b}}{4}-\frac{\left(N_{u}^{*}\right)^{2}}{16 f_{y b} \cdot t}\right\rfloor-\sqrt{2} f_{l e} \cdot l_{t} \frac{s_{b}^{2}}{4}\right\} \\
N_{u}^{*}=\varepsilon_{s} \cdot 2 \cdot l_{t} \cdot t \cdot E_{s} \leq 2 \cdot l_{t} \cdot t \cdot f_{y b}
\end{gathered}
$$

with $s_{b}$ being the spacing of the horizontal steel battens, $l_{t}$ the transversal width of the angles, $t$ the thickness of the angles, and $\varepsilon_{s}$ the axial strain in the angle.

\subsection{Material modeling of concrete}

Material modeling of concrete has been performed according to Ferrotto et. al. [16] by using Concrete Damaged Plasticity (CDP) model available in the software package, by considering modifications for the plasticity parameters to overcome problems related to the triaxial stress state of concrete under high confining stresses. In detail, modification to the yield criterion, the hardening/softening rule and the flow rule are provided by adequate laws for:

- the dilation angle $\psi$ that defines the plastic flow potential; 
- the ratio between the compressive strength under biaxial loading and uni-axial compressive strength $f_{b 0} / f_{c 0}$;

- the ratio Kc between the second stress invariant on the tensile meridian and that on the compressive meridian for the yield function.

In the present work, CDP model was used to perform simulation in the case of confinement under monotonic loads only, therefore the damage variables were not defined.

The parameter $K c$ is evaluated according to Ozbakkaloglu et al. [22] depending on the ratio $f_{b 0} / f_{c 0}$ as follows:

$$
\begin{aligned}
& \frac{f_{b 0}}{f_{c 0}}=1.57 \cdot f_{c 0}^{-0.09} \\
& K c=0.71 \cdot f_{c 0}^{-0.025}
\end{aligned}
$$

The dilation angle is evaluated depending on the external transverse mechanical confinement ratio $\omega_{s t}$.

$$
\begin{gathered}
\omega_{s t}=\omega_{s t, x}+\omega_{s t, y}=\left(\frac{A_{s t, x}}{h \cdot S_{b}}+\frac{A_{s t, x}}{b \cdot S_{b}}\right) \frac{f_{y b}}{f_{c 0}} \\
\psi=56.3 e^{-0.594 \cdot \omega_{s t}}
\end{gathered}
$$

In Eqs. (7) $A_{s t, x}$ and $A_{s t, y}$ are the area of the transverse steel bars along x and y direction respectively, $b$ and $h$ are the dimensions of the concrete cross-section, $s_{b}$ and $f_{y b}$ are the spacing of the horizontal steel battens and the yielding stress, $f_{c 0}$ is the unconfined concrete strength.

A three-stage stress-strain relationship for the plain concrete is therefore used to take into account the modification proposal by Ferrotto et al. [16] depending on the external transverse mechanical confinement ratio $\omega_{s t}$ as well as the dilation angle.

$$
\begin{gathered}
\frac{f_{c}(\varepsilon)}{f_{c 0}}=\left\{\begin{array}{cl}
\frac{x_{1} \cdot \gamma_{1}}{\gamma_{1}-1+x_{1}^{\gamma_{1}}} & 0 \leq \varepsilon \leq \varepsilon_{c 0} \\
1 & \varepsilon_{c 0} \leq \varepsilon \leq \varepsilon_{c 1} \\
\frac{x_{2} \cdot \gamma_{2}}{\gamma_{2}-1+x_{2}^{\gamma_{2}}} & \varepsilon \geq \varepsilon_{c 1}
\end{array}\right. \\
\gamma_{1}=\frac{E_{c}}{E_{c}-\frac{f_{c 0}}{\varepsilon_{c 0}}}, \gamma_{2}=\frac{E_{c}}{E_{c}-\frac{f_{c 0}}{\varepsilon_{c 1}}}, x_{1}=\frac{\varepsilon}{\varepsilon_{c 0}}, x_{2}=\frac{\varepsilon}{\varepsilon_{c 1}} \\
\frac{\varepsilon_{c 1}}{\varepsilon_{c 0}}=0.2107 \cdot \ln \left(\omega_{\mathrm{st}}\right)+1.6455
\end{gathered}
$$

In the above equations, $\varepsilon_{c 0}$ is the unconfined concrete peak strain, $\varepsilon_{c 1}$ is the increasing peak strain affected by the confinement, and $E_{c}$ is the modulus of elasticity of the plain concrete.

\subsection{Simulation of the preloading}

Differently to the case of strengthening of columns without preload, in the presence of loads (a situation that reflects several cases of reinforcement of existing buildings), the con- 
fining element gives its contribution starting from a certain stress/strain level. The external reinforcement should be modeled/activated as soon as the concrete reaches the state of stress at the moment of the application of the reinforcement.

The problem is solved by using the deactivation/reactivation elements technique identified in the software by the "model change interactions". It is thus possible to define the assembled system in such a way to activate the wrapping contribution only when desired.

The simulation of the preload conditions is obtained by articulating the analysis into two steps: i) force applied to the top section of the specimen according to the fixed preload level, ii) the external steel cage is activated and the load test continues until the failure of element.

Specifically, simulations under preload conditions require that in the first step a force/displacement is applied to the non-confined element (with the reinforcement device deactivated) and the stress/strain state at the end of the analysis corresponds to the tensional state relative to the preload level. In the second step, the confinement device becomes active in deformed conditions, characterized by the congruence of the nodal displacements of the concrete meshes, but with zero stress/strain state.

Axial stresses, lateral stresses and axial total strains corresponding to the middle section were recorded during the analysis.

The time analysis-stress and the stress-strain response are plotted in Fig. 2 for the case of compression test with no preload and with two different levels of preloading i.e. np 0.7 and 0.9. It is possible to see that, coupled with the strain lag activation of the steel cage (and therefore the providing of the lateral confinement pressure), the strength decreases as the imposed preload level increases (Fig. 2).

In Fig. 3 the stress and strain distributions in the specimen confined with steel jackets are shown for three significant steps of the numerical process:

- The end of the first step (Fig. 3 a-b) in which the unconfined concrete reached the preload without any contribution of the jacket;

- The beginning of the second step at increment 0 (Fig. 3 c-d) in which the concrete keeps the same stress/strain configuration of the previous step and the jacket becomes "active" in a virgin stress/strain state but having the same shape of the column;

- A certain increment of the second step (Fig. 3 e-f) in which the steel jackets contribute to the global response. In this phase, the strain compatibility is still given by "tie constrains interaction" and the strains in the jackets are lower than the cylinders because they are computed in the analysis before the preloading step.
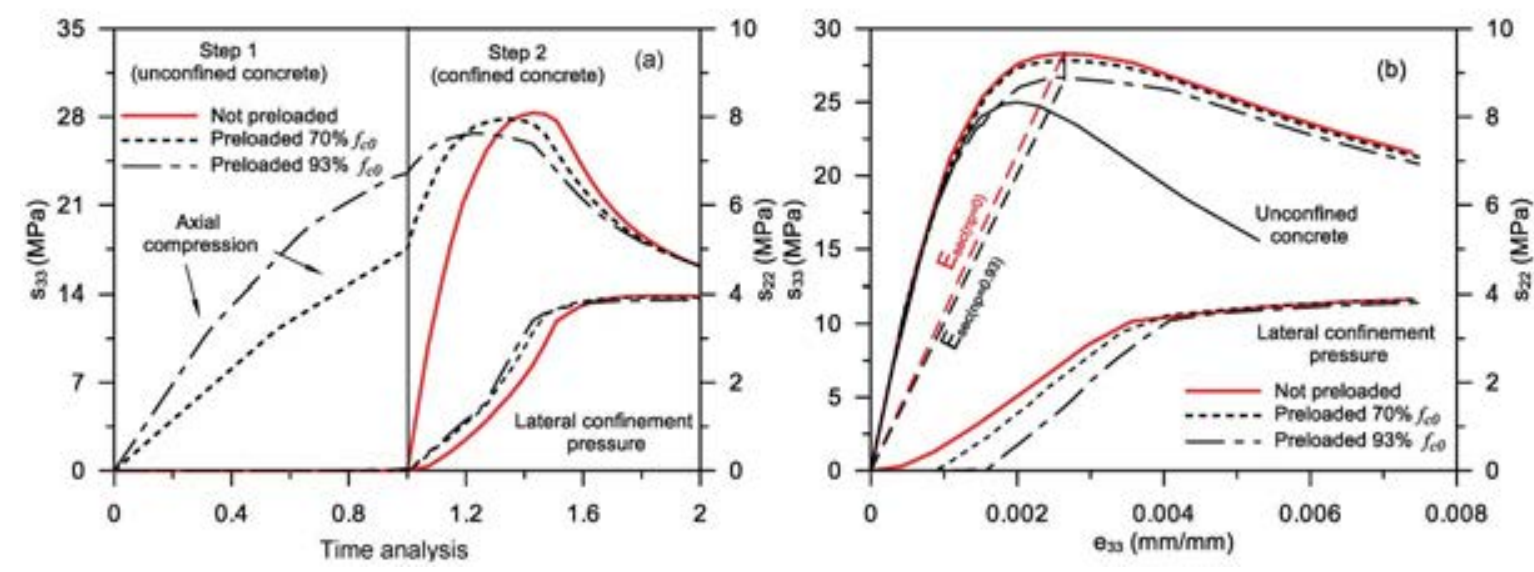

Figure 2: FE computational process (a) and Axial stress-strain behavior and lateral pressure evolution (b). 


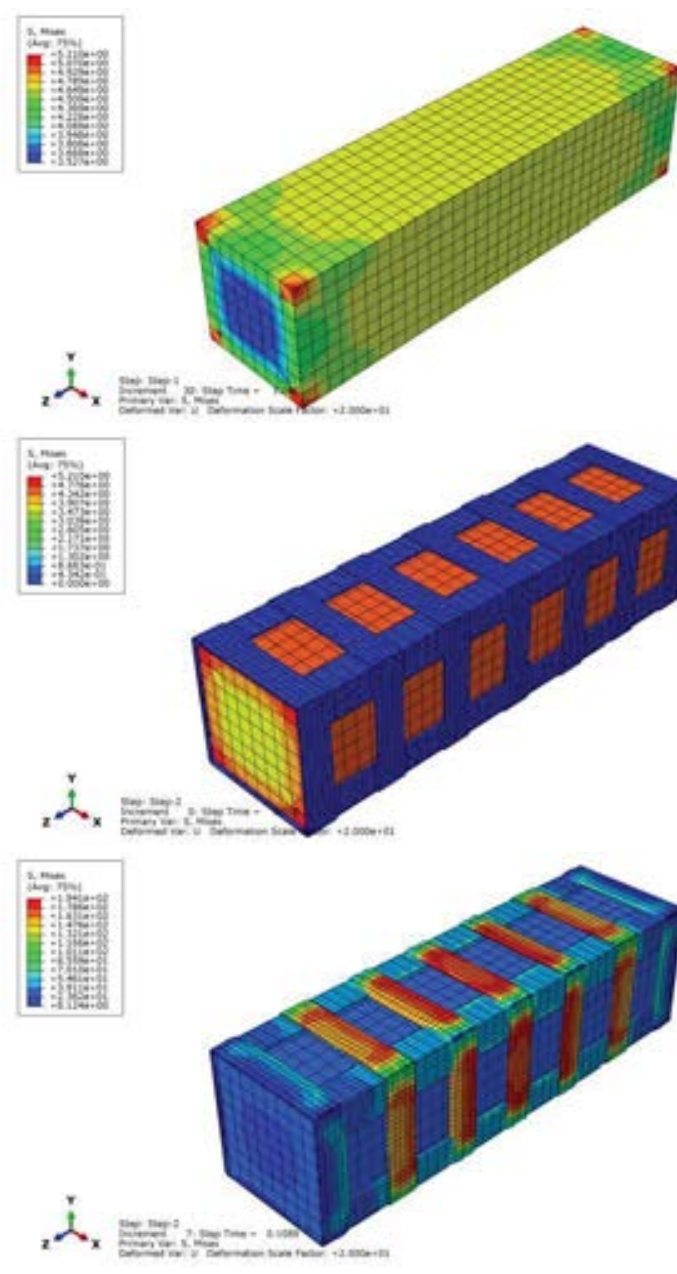

(a)
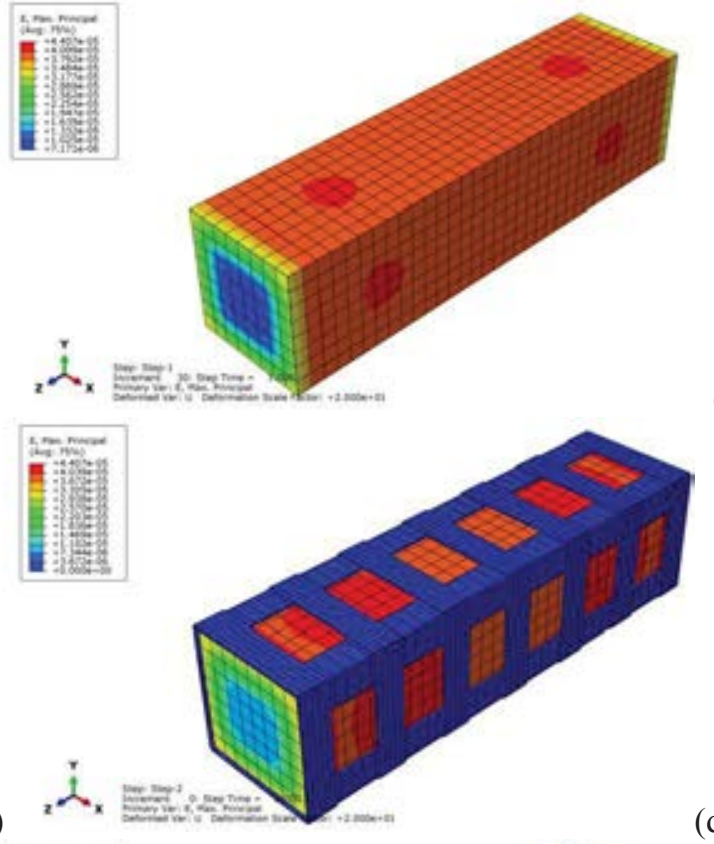

(b)

(d)

(e)

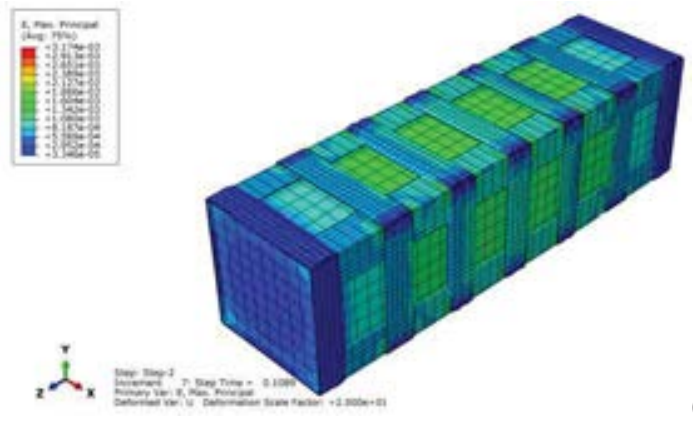

(f)

Figure 3: Stresses and strains distribution in the model (case 2) during: end of first step (a and b); second step at increment 0 (c and d) and increment 7 (e and f)

\section{EXPERIMENTAL TESTING}

In the following, a brief description of an experimental investigation previously carried out by the authors is provided. For more details, please refer to the original paper by Ferrotto et al. [17]. It has to be pointed out that, in the frame of the present paper, additional tests carried out for different concrete age specimens are presented to improve the number of data and the reliability of the findings.

The experimental program consisted of compression tests on columns strengthened by means of steel cages under different load conditions. Tests on unreinforced, reinforced before any loading and reinforced after axial loading at a fixed rate of the capacity were performed for low, medium and high level of the preload.

Fifteen compressive tests were performed. Among the total number of tests, ten columns were tested with an average concrete age of 146 days, while five additional columns were tested with an average concrete age of 530 days. The reason was to observe the effect of the aging of the concrete on the compressive capacity including sustained loads.

The external steel cages used for the strengthening were defined according to Fig. 1, connecting angles and battens by welding. For both angles and battens, no mortar was uses at the contact surfaces with the concrete columns. 
The steps of the tests of the preloaded specimens are listed hereinafter:

- Preloading: during this stage, the measuring of the shortening in the middle height of the specimens allowed to identify the stress-strain behavior of the unconfined concrete. Once the target preload was reached, stabilization of the load and acquisition of creep strains were performed;

- Strengthening: After preloading, digital transducers were removed from the concrete specimens and steel jackets were applied by welding;

- Unloading: specimens were unloaded and transferred to the load testing machine, strain gauges were applied to the steel cages and the digital transducers to the concrete specimens as in the case of the preload tests. Moreover, long digital transducers were assembled at the four corners of the specimens;

- Collapse test: the specimens were loaded up to collapse, recording axial strains of the columns and axial and lateral strains on the steel jackets.

Preloading was applied in a three-dimensional steel testing frame system composed by three rigid steel beams and four steel bars (diameter of $80 \mathrm{~mm}$ ) fixed to the lower floor structure. Hydraulic jack and a load cell were placed between the central steel beam and the concrete specimen to apply the compressive force monitored by a digital data acquisition system.

The welding of the steel cages was done while specimens were under a certain assigned stress/strain state. The apparatus for the preloading is shown in Fig. 4 coupled with a picture of a specimen reinforced under sustained loads.
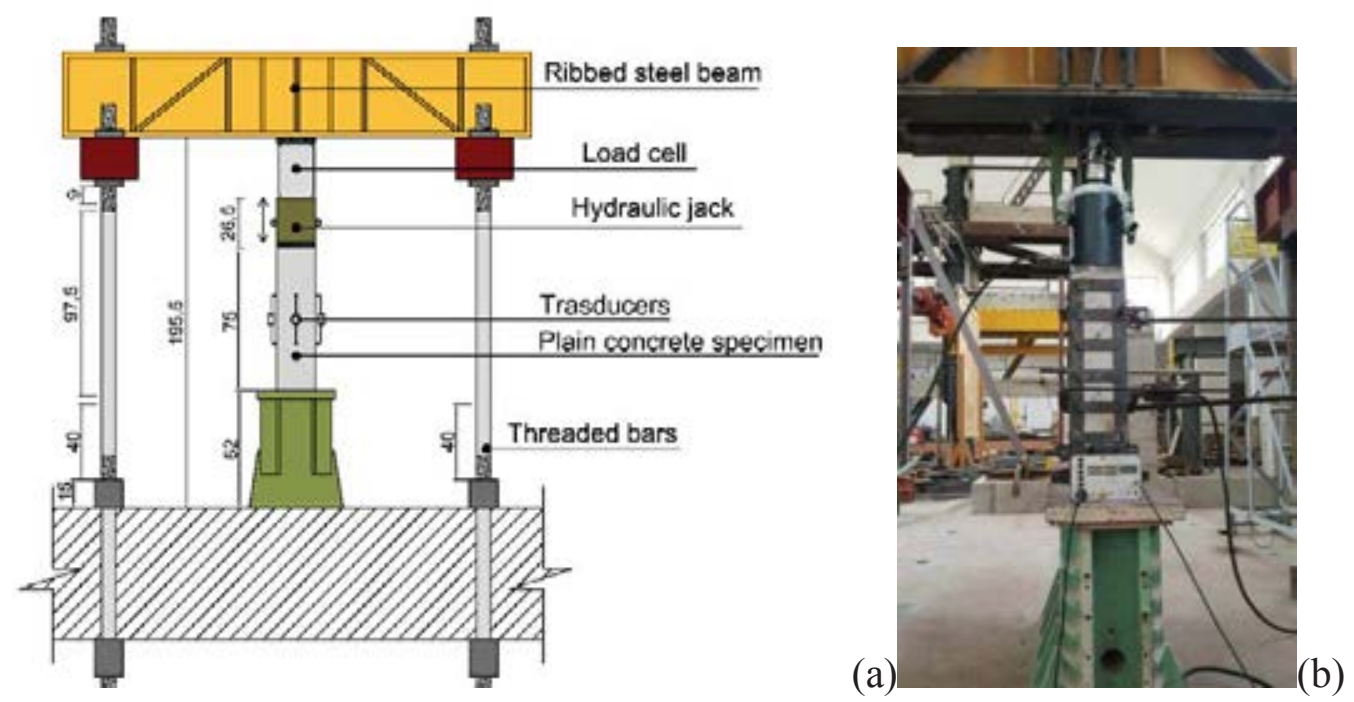

Figure 4: Preloading frame device (a); Strengthening of a specimen under sustained load.

Axial strains on the column specimens were measured by using two systems of digital transducers. Four of these had a gauge length equal to the internal length of the specimen (750 $\mathrm{mm}$ ) and were placed at the corners. Four other transducers were placed on the lateral faces of the column at the middle height, with a gauge length of $220 \mathrm{~mm}$. The double system of transducers allowed the recognition of strain concentration in the middle of the specimens. Strains on the steel cages were also recorded by means of "linear type" strain gauges with a gauge length of $13 \mathrm{~mm}$. Horizontal and vertical strain gauges were bonded to the steel battens in correspondence of the middle height of the column and on the external surface of the steel angles at the top, middle and bottom respectively. This measurement layout allowed to obtain average strains and stresses of the battens (controlling, therefore, the evolution of the lateral pres- 
sure) and average strains and stresses of the angles (obtaining the axial load carried out by the angles). Details of the measurement setup are reported in Fig. 5.
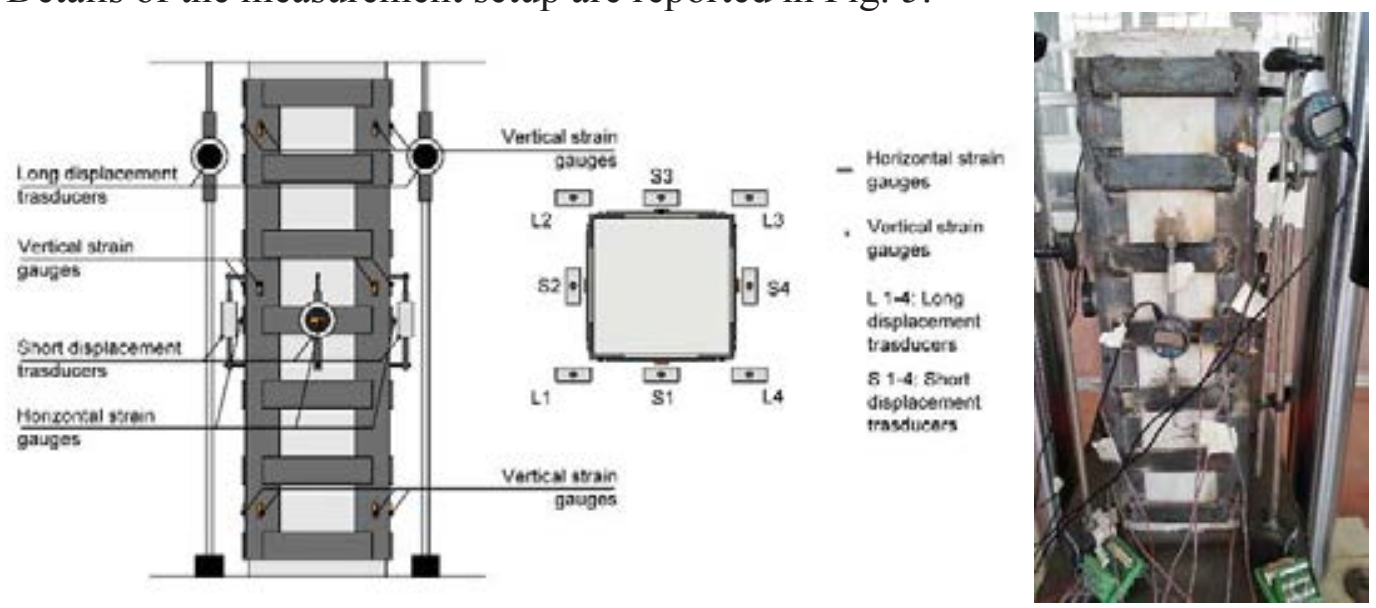

Figure 5: Arrangement of the measurement system.

\subsection{Testing under sustained loads}

The target strength for the concrete was $20 \mathrm{MPa}$. Concrete mixture was composed by CEM I $32.5 \mathrm{R}$, water, sand and aggregate with size varying from 0 to $20 \mathrm{~mm}$, having proportion in weight $1: 1.51: 0.384: 0.353$. Concrete cubes having size of $150 \mathrm{~mm}$ were made during the concrete casting, for testing the compression strength after 28 days. The tests were performed according to UNI EN 12390 Standards. Test results provided for the plain concrete a cubic compressive strength of $19.99 \mathrm{MPa}$ (and therefore, a cylinder compressive strength of 16.59 $\mathrm{MPa}$ ), while the target strength fc 0 was considered equal to $16.75 \mathrm{MPa}$ based on the average from cubes and two full-scale plain concrete specimens $(633.94 \mathrm{kN}$ and $715.27 \mathrm{kN}$ with average max load and stress of $674.58 \mathrm{kN}$ and $16.86 \mathrm{MPa}$ respectively).

Specimens were labeled depending on the type of preload $(\mathrm{P} \#)$, the type of reinforcement (S) and the number of the specimen \#. For example, specimen P0S1 referred to 0 preload force, specimen strengthened with steel jackets (S), specimen n1, while P60S2 refers to a preload force nominally equal to the $60 \%$ of the strength, specimen strengthened with steel jackets, specimen $\mathrm{n} 2$. Table 1 lists the details of each test.

\begin{tabular}{llll}
\hline Specimen & Type of test & $\begin{array}{l}\text { Preload level }(\%) \\
\text { and force }(\mathrm{kN})\end{array}$ & $\begin{array}{l}\text { Average concrete } \\
\text { age }(\text { days })\end{array}$ \\
\hline NC1-2 & Plain concrete & $/$ & 146 \\
P0S1-2 & Confined & $/$ & 146 \\
P0S3 & & 146 \\
P40S1 & Preloaded and confined & $40 / 270$ & 146 \\
P60S1-2 & Preloaded and confined & $60 / 402$ & 146 \\
P60S3 & & & 530 \\
P70S1 & Preloaded and confined & $70 / 483$ & 146 \\
P70S2 & & & 530 \\
P80S1-2 & Preloaded and confined & $80 / 530$ & 146 \\
P80S3 & Preloaded and confined & $90 / 603$ & 530 \\
P90S1 & & & 530 \\
\hline
\end{tabular}


Table 1: Type of tests.

Preload tests had variable duration depending on the evolution of creep strains after the maximum load was reached. The time of preloading for each specimen was: specimen P40S1, 10 hours, P60S1-3, 11, 10 and 12 hours respectively, P70S1-2 6.5 and 8 hours respectively, P80S1-3 7.5, 5 and 8 hours respectively, and P90S1 7 hours.

In the case of low preload levels, i.e. for preloaded specimens at $40 \%$ and $60 \%$ of the strength, creep strains evolution was restricted and stable. Otherwise, for high preload forces (i.e. $70-90 \%$ ), higher creep strains evolution was observed followed by smeared cracking of the specimens.

During the last stage of the preloading, specimens were strengthened by the steel jackets; then, after the unloading and the transferring to the load testing machine, specimens were equipped with digital transducers and strain gauges before the final collapse tests. For more details, please refer to the original treatment of the authors [17].

\subsection{Failure compressive tests}

Compressive load-strain response of the strengthened specimens was characterized by load increasing behavior up to the maximum load capacity, followed by a strain-softening behavior. Compression tests were terminated in correspondence to a reduction of $85 \%$ of the maximum load. In some cases, a premature failure of the confinement device occurred by the failure of the welding between steel angle and strip causing a high loss of load (as for specimen P0S2). Some pictures of strengthened specimens at failure are shown in Fig. 6.

The results showed a significant increase in load and deformational capacity compared to the compression response of unconfined specimens. It is important to note that this increase in the load capacity was due to the global contribution provided by the response of the confined concrete and the angles.

Compression tests of preloaded specimens showed differences with respect to the nonpreloaded ones. Load-strain curves were affected by a reduction of the maximum load-bearing capacity and a significant reduction in the secant stiffness. This effect was caused by the strain-lag (lower confinement lateral pressure for a given value of axial strain with respect to the non-preloaded specimens) directly proportional to the applied preload level as for the load carried out by the angles. These reductions can be observed in Table 2 that summarizes the experimental results (and subsequently the comparisons with the FE predictions).

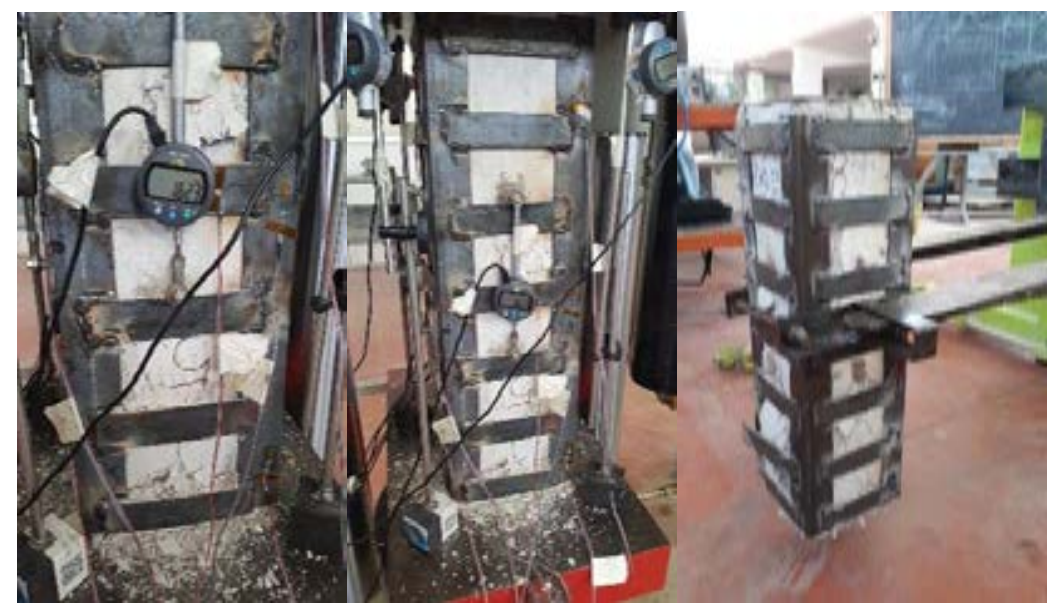

Figure 6: Strengthened specimens at failure. 


\section{COMPARISONS BETWEEN EXPERIMENTAL RESULTS AND FE PREDICTIONS}

The comparisons between experimental results and FE predictions are presented hereinafter. The plasticity parameters of the concrete for the numerical model were calculated by using Eqs. (5-9), while the steel angles equivalent yielding stress was calculated by using Eq. (2). An equivalent elasticity modulus has been assigned to the steel angles to consider indirectly the sliding between the steel and concrete contact surfaces according to Ferrotto et al. [17].

The effect of the sustained loads on the compressive strength of concrete need to be considered for the modification of the compressive response of the plain concrete depending on:

i) the level of sustained load applied before strengthening (preloading): this aspect modifies, according to the statements presented in section 3.4, the load-strain response of the confined concrete because of the strain-lag effects;

ii) the modification of the plain concrete strength due to high sustained stresses: this aspect was considered according to the findings of Rüsch [23] and Tasevski et al. [24].

The first aspect was assessed by a modification of the hardening/softening function to consider the reduction of the confinement effects due to the strain-lag. This causes a lower equivalent compressive peak strain compared to confined concrete without preload. Besides, this effect resulted in much higher strain as the preload level increases. Differently from Eq. (11), in the frame of this study, a new equation (Eq. 12) is proposed based on non-linear regression of the numerical results depending on the mechanical confinement ratio and the preloading level. The proposed equation considers the increasing of the concrete peak strain due to the confinement and, at the same time, the reduction of the latter due to the preloading effects by the parameter $k_{(n p)}$. It is remarked that, by using Eq. (12), in the case of columns without any external reinforcement and no preload, the behavior of the plain concrete is obtained.

$$
\begin{aligned}
& \frac{\varepsilon_{c 1}}{\varepsilon_{c 0}}=k_{\left(n_{p}\right)} \cdot\left(1+1.6877 \cdot \omega_{\mathrm{st}}\right) \\
& k_{\left(n_{p}\right)}=1+0.0785 \cdot n_{p}-0.4695 \cdot n_{p}^{2}
\end{aligned}
$$

The second aspect is assessed by a simplified analytical equation to predict the compressive strength of concrete influenced by high sustained loads according to Tasevski et al. [24]. The proposed equation is selected in the present study to be used for the assessment of the numerical model.

$$
\begin{aligned}
& f_{c}(n p)=1 \cdot f_{c 0} \quad \text { if } \quad n_{p} \leq 0.75 \\
& f_{c}(n p)=\left(1.6-0.8 \cdot n_{p}\right) \cdot f_{c 0} \quad \text { if } \quad n_{p} \geq 0.75
\end{aligned}
$$

As a result, in Fig. $7 \mathrm{a}-\mathrm{b}$, the reduction parameter $k_{(n p)}$ and the uni-axial stress-plastic strain laws used for the analyses are shown for the different preloading levels according to the experimental tests. The others plasticity parameters as well as the plain concrete strengths used for the numerical analyses are shown in Table 3. Finally, the experimental-numerical comparisons in terms of load-strain response are shown in Fig. 8, highlighting the suitability of the FE model to reproduce the compressive behavior of the strengthened columns under the different levels of preload. 


\begin{tabular}{llll}
\hline Specimen & $\begin{array}{l}\mathrm{P}_{\max }-\text { Exp } \\
(\mathrm{kN})\end{array}$ & $\begin{array}{l}\mathrm{FE} \\
(\mathrm{kN})\end{array}$ & FE/ $\mathrm{P}_{\max }-$ Exp \\
\hline P0S1 & 1364.80 & & 0.97 \\
P0S2 & 1402.97 & 1317.88 & 0.94 \\
P0S3 & 1341.60 & & 0.98 \\
P40S1 & 1297.30 & 1295.00 & 1.00 \\
P60S1 & 1274.14 & & 1.00 \\
P60S2 & 1237.31 & 1271.40 & 1.03 \\
P60S3 & 1214.10 & & 1.05 \\
P70S1 & 1179.80 & 1222.48 & 1.04 \\
P70S2 & 1224.59 & & 1.00 \\
P80S1 & 1203.01 & & 0.98 \\
P80S2 & 1323.13 & 1182.37 & 0.89 \\
P80S3 & 1141.30 & & 1.04 \\
P90S1 & 1153.24 & 1120.00 & 0.97 \\
\hline
\end{tabular}

Table 2: Experimental and numerical results.
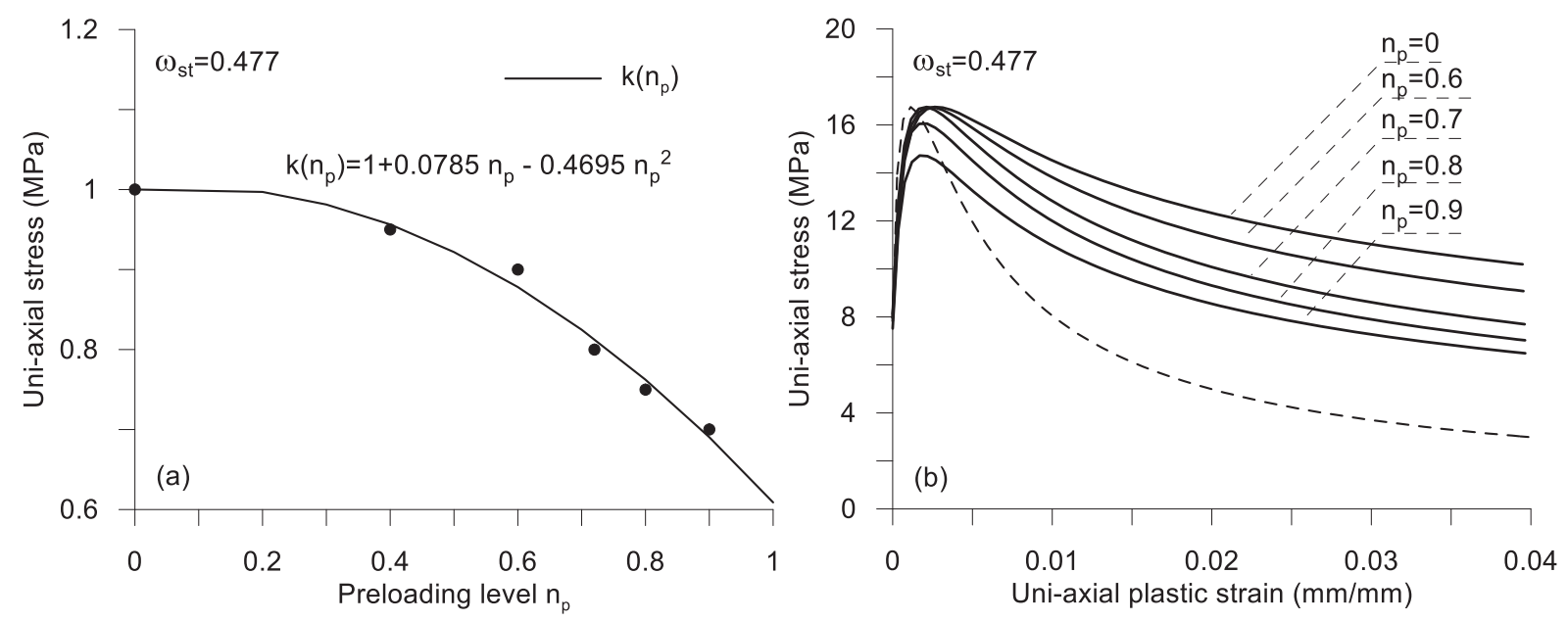

Figure 7: Reduction parameter k(np) (a); uni-axial stress-plastic strain laws used for the analyses (b).

\begin{tabular}{llllll}
\hline Specimen & $\begin{array}{l}\text { Concrete } \\
\text { strength }(\mathrm{MPa})\end{array}$ & $\begin{array}{l}\text { Dilation } \\
\text { angle }\end{array}$ & $\mathrm{Kc}$ & $f_{b 0} / f_{c 0}$ & $\mathcal{E}_{c 1}$ \\
\hline P0S & 16.75 & 42.45 & 0.736 & 1.21 & 0.00362 \\
P40S & 16.75 & 42.45 & 0.736 & 1.21 & 0.00350 \\
P60S & 16.75 & 42.45 & 0.736 & 1.21 & 0.00320 \\
P70S & 16.75 & 42.45 & 0.736 & 1.21 & 0.00289 \\
P80S & 16.08 & 41.89 & 0.736 & 1.22 & 0.00275 \\
P90S & 14.74 & 40.85 & 0.738 & 1.23 & 0.00257 \\
\hline
\end{tabular}

Table 3: Plasticity parameters for the different case analyses. 


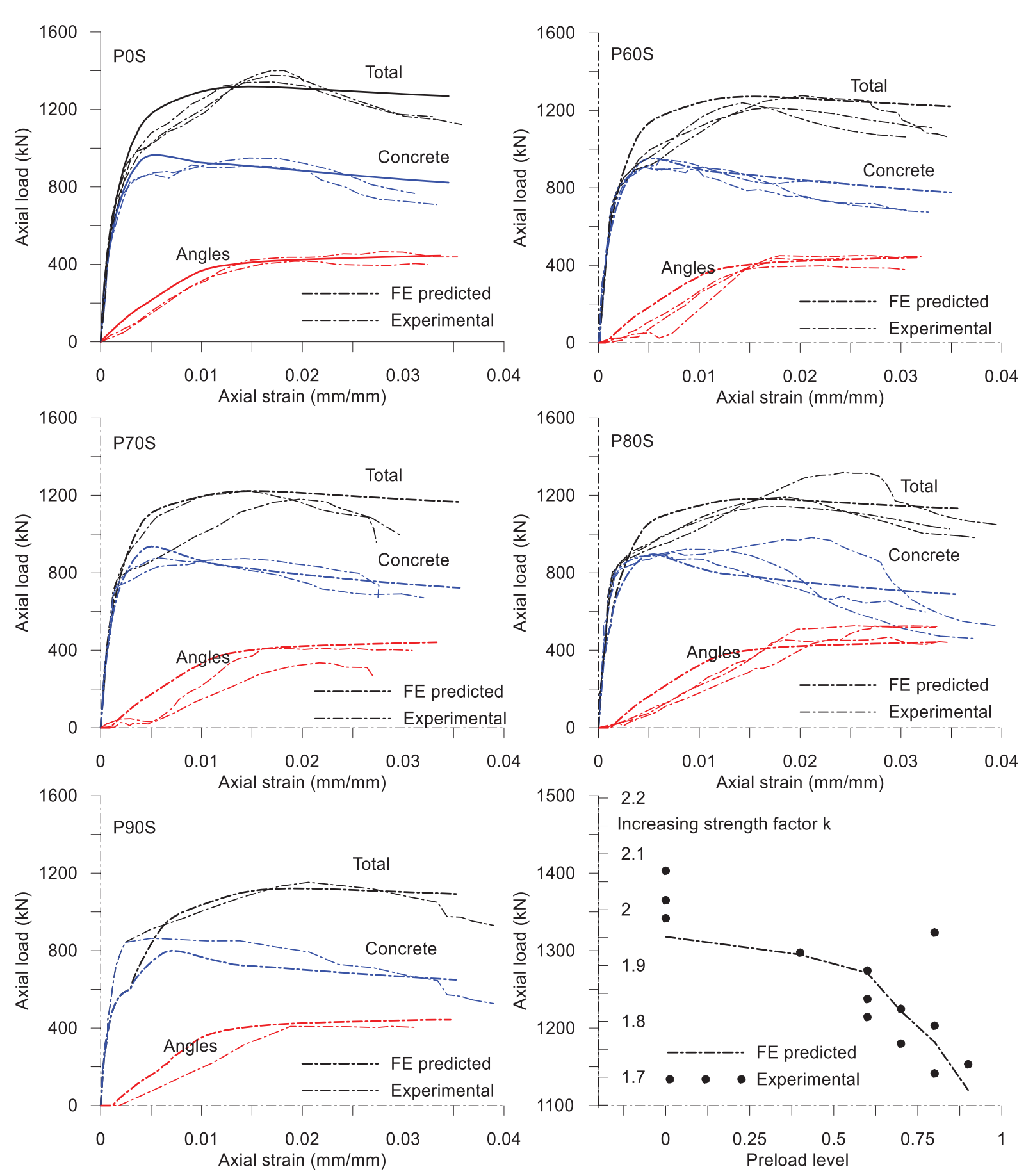

Figure 8: Experimental-numerical comparisons.

\section{CONCLUSIONS}

In this paper, the evaluation of the compressive behavior of columns strengthened by means of external steel cages considering the effect of the preload at the moment of strengthening was investigated by experimental and numerical approaches. Compared to the loadbearing capacity of columns strengthened without preload, it was observed that there is a reduction of the capacity because of the preload depending on: 
- A reduction of the compressive strength of the concrete induced by high sustained loading;

- The strain-lag effects of the confining device due to the preload.

Moreover, the above-mentioned effects are more significant with the increasing of the levels of preload.

A numerical FE model was assessed and used for the experimental-numerical comparisons, showing its reliability on the realistic prediction of the physical process and the results. The FE model can be used for subsequent accurate predictive scenarios including different mechanical properties for the concrete and the steel cages.

\section{REFERENCES}

[1] C. Ma, N.M. Apandi, C.S.Y. Sofrie, J.H. Ng, W.H. Lo, A.Z. Awang, W. Omar, Repair and rehabilitation of concrete structures using confinement: a review. Construction and Buildilg Material, 133, 502-515, 2017.

[2] P. Colajanni, S. Pagnotta, G. Testa, Comparison of fully non-stationary artificial accelerogram generation methods in reproducing seismicity at a given site. Soil Dynamics and Earthquake Engineering, 133, 2020. https://doi.org/10.1016/j.soildyn.2020.106135.

[3] P. Colajanni, S. Pagnotta, A. Recupero, N. Spinella, Shear resistance analytical evaluation for RC beams with transverse reinforcement with two different inclinations. Materials and Structures, 53 (1), 18, 2020. https://doi.org/10.1617/s11527-020-1452-8.

[4] R. Benzaid, H. Mesbah, N. Chikh. FRP-confined concrete cylinders: axial compressionexperiments and strength model. Journal of Reinforced Plastic Composites; 29(16), 2469-88, 2010.

[5] F. Micelli, R. Modarelli. Experimental and analytical study on properties affecting the behavior of FRP-confined concrete. Composites Part B, 45(1):1420-31, 2013.

[6] M.F. Ferrotto, O. Fischer, L. Cavaleri. A strategy for the finite element modeling of FRP-confined concrete columns subjected to preload. Engineering Structures, 173, 1054-1067, 2018.

[7] M.F. Ferrotto, O. Fischer, R. Niedermeier, Experimental investigation on the compressive behavior of short term preloaded CFRP-confined concrete columns, Structural Concrete, 1-14, 2017. https://doi.org/10.1002/suco.201700072.

[8] M.F. Ferrotto, O. Fischer, L. Cavaleri, Analysis-oriented stress-strain model of CRFPconfined circular concrete columns with applied preload. Materials and Structures, 51(44), 2018. https://doi.org/10.1617/s11527-018-1169-0.

[9] G. Campione, F. Cannella, M.F. Ferrotto, M. Gianquinto, Compressive behavior of FRP externally wrapped R.C. column with buckling effects of longitudinal bars. Engineering Structures, 168, 809-818, 2018.

[10] J.M. Adam, S. Ivorra, E. Giménez, J.J. Moragues, C. Mirigall, P.A. Calderón, Behaviour of axially loaded RC columns strengthened by steel angles and strips. Steel Composite Structures, 7, 405-419, 2007. 
[11] J.M. Adam, S. Ivorra, F.J. Pallarés, E. Giménez, P.A. Calderón, Axially loaded RC columns strengthened by steel caging. Finite element modelling. Construction and Building Material, 23, 2265-2276, 2009.

[12] R. Montuori, V. Piluso, Reinforced concrete columns strengthened with angles and battens subjected to eccentric load, Engineering Structures. 31, 539-550, 2009.

[13] V. Badalamenti, G. Campione, M.L. Mangiavillano, Simplified Model for Compressive Behavior of Concrete Columns Strengthened by Steel Angles and Strips. Journal of Engineering Mechanics ASCE, 136, 230-238, 2010.

[14] G. Campione, L. Cavaleri, M.F. Ferrotto, G. Macaluso, M. Papia, Efficiency of stressstrain models of confined concrete with and without steel jacketing to reproduce experimental results. The Open Construction and Building Technology Journal, 10 (Suppl 1: M4) (2016) 65-86.

[15] G. Campione, L. Cavaleri, F. Di Trapani, M.F. Ferrotto, Frictional effects on structural behavior of no-end-connected steel-jacketed RC columns: Experimental results and new approaches to model numerical and analytical response. Journal of Structural Engineering ASCE 143, 04017070, 2017, https://doi.org/10.1061/(ASCE)ST.1943541X.0001796.

[16] M.F. Ferrotto, L. Cavaleri, F. Di Trapani, FE modeling of Partially Steel-Jacketed (PSJ) RC columns using CDP model. Computers and Concrete, 22(2), 143-152, 2018.

[17] M.F. Ferrotto, L. Cavaleri, M. Papia, Compressive response of substandard steel jacketed RC columns strengthened under sustained loads: from the local to the global behavior, Construction and Building Materials. 179, 500-511, 2018.

[18] A.R. Takeuti, J.B. de Hanai, A. Mirmiran, Preloaded RC columns strengthened with high-strength concrete jackets under uniaxial compression. Materials and Structures, 41, 1251-1262, 2008.

[19] G.K. Vandoros, S.E. Dritsos, Axial preloading effects when reinforced concrete columns are strengthened by concrete jackets. Progress in Structural Engineering Materials 8, 79-92, 2006.

[20] Y. Pan, L. Wan, X. Wu. Analysis-oriented stress-strain model of CFRP confined concrete with preload. Journal of Southwest Jiaotong University;50(3):461-5, 2015. (In Chinese).

[21] ABAQUS (2013), ABAQUS Theory and User Manuals, Version 6.13-1.

[22] T. Ozbakkaloglu, A. Gholampour, J.C. Lim, Damage-plasticity model for FRP-confined normal-strength and high-strength concrete, Journal of Composites for Construction ASCE, 20(6), 04016053, 2016.

[23] H. Rüsch. Experimental determination of the effect of the duration of loading on the resistance and deflection. (in German: "Versuche zur Bestimmung des Einflusses der Zeit auf Festigkeit und Verformung."). Report. IABSE congress report, 5, 237-244, 1956.

[24] D. Tasevski, M. Fernández Ruiz, A. Muttoni, Assessing the compressive strength of concrete under sustained actions: From refined models to simple design expressions. Structural Concrete.1-15, 2019. https://doi.org/10.1002/suco.201800303 